\title{
The influence of alpha-melanocortin enantiomers on acetaminophen-induced hepatis in mice
}

\author{
Petra Turčićc ${ }^{*}$, Karlo Houra ${ }^{2}$, Mirna Bradamante ${ }^{3}$, Paško Konjevoda ${ }^{4}$, Tomislav Kelava ${ }^{5}$, Nikola Štambuk ${ }^{4}$ \\ From 18th Scientific Symposium of the Austrian Pharmacological Society (APHAR). Joint meeting with the \\ Croatian, Serbian and Slovenian Pharmacological Societies. \\ Graz, Austria. 20-21 September 2012
}

\section{Background}

L-alpha-Melanocortin is a strong inhibitor of inflammation. It is a promising new anti-inflammatory and hepatoprotective peptide. Consequently, its melanocortin receptors $\left(\mathrm{MC}_{1}, \mathrm{MC}_{3}, \mathrm{MC}_{4}\right.$ and $\left.\mathrm{MC}_{5}\right)$ could be possible targets for the development of new antiinflammatory drugs for chronic inflammatory liver disease. For a long time it has been believed that only the L-enantiomers of amino acids are present in higher animals, but recent investigations show that $\mathrm{D}$-amino acids also exhibit physiological effects in vivo, despite their very small quantities. The aim of this study was to compare hepatoprotective effects of L-alpha-melanocortin and D-alpha-melanocortin using the acetaminophen model of chemical liver damage in male CBA mice.

\section{Methods}

Tested substances were applied intraperitoneally $60 \mathrm{~min}$ utes prior to the intragastric application of acetaminophen $(150 \mathrm{mg} / \mathrm{kg})$. Animals were sacrificed 24 hours after the administration of acetaminophen. The criteria for monitoring hepatoprotective effects of the tested substances were biochemical parameters (AST and ALT) and histopathological analysis.

\section{Results}

The results obtained by the histopathological analysis and biochemical findings show potent hepatoprotective and anti-inflammatory effects of L-alpha-melanocortin in the liver, and suggest the possibility of modulating liver inflammation by means of melanocortin molecules and related receptors. D-alpha-melanocortin did not show any hepatoprotective effects in vivo.

\section{Conclusions}

Our results show that peptide enantiomerism influences the protective effects of alpha-melanocortin peptides in vivo. This concept may be used to modulate peptide function in vivo and antibody binding assay in vitro.

\section{Acknowledgements}

The support of the Croatian Ministry of Science, Education and Sports is gratefully acknowledged (grant no. 098-0982929-2524).

\section{Author details}

${ }^{1}$ Department of Pharmacology, Faculty of Pharmacy and Biochemistry, University of Zagreb, 10000 Zagreb, Croatia. ${ }^{2}$ St. Catherine's Hospital, 49210 Zabok, Croatia. ${ }^{3}$ Department of Dermatology and Venerology, University Hospital Center Zagreb, 10000 Zagreb, Croatia. ${ }^{4}$ Ruđer Bošković Institute, 10000 Zagreb, Croatia. ${ }^{5}$ Department of Physiology and Immunology, School of Medicine, University of Zagreb, 10000 Zagreb, Croatia.

Published: 17 September 2012

doi:10.1186/2050-6511-13-S1-A77

Cite this article as: Turčić et al:: The influence of alpha-melanocortin enantiomers on acetaminophen-induced hepatis in mice. BMC

Pharmacology and Toxicology 2012 13(Suppl 1):A77.

\footnotetext{
* Correspondence: petra.turcic@gmail.com

'Department of Pharmacology, Faculty of Pharmacy and Biochemistry,

University of Zagreb, 10000 Zagreb, Croatia

Full list of author information is available at the end of the article
}

(c) 2012 Turčić et al; licensee BioMed Central Ltd. This is an Open Access article distributed under the terms of the Creative Commons 